\title{
Inflammatory Bowel Disease in Juvenile Idiopathic Arthritis Patients Treated with Biologics
}

\author{
Deborah Barthel, Gerd Ganser, Rolf-Michael Kuester, Nils Onken, Kirsten Minden, \\ Hermann Josef Girschick, Anton Hospach, and Gerd Horneff
}

\begin{abstract}
Objective. Evolving inflammatory bowel disease (IBD) is a matter of interest in patients with juvenile idiopathic arthritis (JIA) and might be associated with JIA therapy.

Methods. Data from the German biologics registry (Biologika in der Kinderrheumatologie; BiKeR) from 2001 to 2013 were analyzed.

Results. There were 3071 patients with 8389 patient-years (PY) of observation followed. IBD was diagnosed in 11 patients, 8 with Crohn disease and 3 with ulcerative colitis. IBD incidence in patients with JIA was $1.31 / 1000$ PY and higher than published IBD incidences in pediatric populations. Compared with the total BiKeR cohort, patients with IBD more commonly had enthesitis-related arthritis, extended oligoarthritis, psoriatic arthritis, and also rheumatoid factor (RF)-negative polyarthritis. No IBD occurred in patients with systemic JIA or RF-positive polyarthritis. In patients treated with methotrexate (MTX), the IBD incidence was significantly lower compared with patients not treated with MTX. Etanercept (ETN) monotherapy, but not the combination of ETN and MTX, was associated with an increased incidence of IBD.

Conclusion. Incidence of IBD in patients with JIA is higher than in the population. MTX turned out to be protective, even in combination with ETN. (First Release September 15 2015; J Rheumatol 2015;42:2160-5; doi:10.3899/jrheum.140472)
\end{abstract}

Key Indexing Terms:

JUVENILE IDIOPATHIC ARTHRITIS METHOTREXATE

BIOLOGICS
INFLAMERCEPT
INATORY BOWEL DISEASE

Juvenile idiopathic arthritis (JIA) is the most common chronic inflammatory disease in children, with an incidence of up to 15 cases/year per 100,000 children ${ }^{1,2,3}$. There are several treatment options, because of the differences in the pathogenesis and the clinical features of the 8 JIA subtypes. Treatment recommendations depend on clinical features, such as disease severity and prognostic factors, but also on the efficacy of the medical treatment, including the risk of side effects ${ }^{4,5,6}$. In some patients with only a few affected joints, intraarticular injections with corticosteroids and

From the Department of Pediatrics, Asklepios Klinik Sankt Augustin, Sankt Augustin; Department of Pediatric Rheumatology, St. Josef-Stift Sendenhorst, Sendenhorst; Asklepios Rheumazentrum Hamburg, Hamburg; Pediatric Practice, Lueneburg; Deutsches Rheuma-

Forschungszentrum, Berlin; Department of Pediatrics, Vivantes Klinikum im Friedrichshain, Berlin; Department of Pediatrics, Klinikum Stuttgart, Stuttgart, Germany.

D. Barthel, MD, Department of Pediatrics, Asklepios Klinik Sankt Augustin; G. Ganser, MD, Department of Pediatric Rheumatology, St. Josef-Stift Sendenhorst; R.M. Kuester, MD, Senior Consultant, Asklepios Rheumazentrum Hamburg; N. Onken, MD, Pediatric Practice; K. Minden, MD, Deutsches Rheuma-Forschungszentrum; H.J. Girschick, MD, Department of Pediatrics, Vivantes Klinikum im Friedrichshain; A. Hospach, MD, Department of Pediatrics, Klinikum Stuttgart; G. Horneff, MD, Department of Pediatrics, Asklepios Klinik Sankt Augustin. Address correspondence to Dr. D. Barthel, Department of Pediatrics, Asklepios Clinic Sankt Augustin, Sankt Augustin, Arnold-Janssen-Str. 29, D-53757 Germany.E-mail: d.barthel@asklepios.com

Accepted for publication July 1, 2015. symptomatic therapy with nonsteroidal antiinflammatory drugs (NSAID) can be sufficient. Most patients with polyarticular and systemic-onset JIA are often treated initially with disease-modifying antirheumatic drugs (DMARD), most commonly methotrexate (MTX) ${ }^{7}$. In the case of ineffectiveness or intolerance to first-line therapy or severe comorbidity, e.g., uveitis, biologic treatment options exist. The tumor necrosis factor- $\alpha$ (TNF- $\alpha$ ) receptor immunoglobulin fusion protein etanercept (ETN) has been shown to be effective in all JIA subtypes, except systemic-onset JIA $8,9,10,11$. TNF- $\alpha$ is involved as a proinflammatory cytokine in the pathophysiology of inflammation, so its inhibition can be effectively used for JIA treatment ${ }^{12}$.

Inflammatory bowel disease (IBD) is a matter of interest in patients with JIA because cases have been described of IBD onset upon treatment with ETN ${ }^{13,14,15,16,17}$. TNF- $\alpha$ secretion is also involved in the pathogenesis of $\mathrm{IBD}^{18}$. The TNF- $\alpha$ antibodies adalimumab (ADA) and infliximab (IFX) are both approved for the treatment of moderate to severe Crohn disease (CD) and ulcerative colitis (UC) ${ }^{19}$, while ETN failed to be effective in patients with $\mathrm{CD}^{20}$.

IBD occurring in patients with JIA might be a comorbidity because it has been described for adults with spondyloarthropathies ${ }^{21}$. Otherwise, arthritis could represent an extraintestinal manifestation of IBD occurring later. It is unclear whether IBD incidence in patients with JIA is

Personal non-commercial use only. The Journal of Rheumatology Copyright (C) 2015. All rights reserved. 
increased as a consequence of JIA therapy with ETN or for other reasons. The primary objective of our work was to find out how drug exposure could influence the occurrence of an IBD in patients with JIA.

\section{MATERIALS AND METHODS}

Data from the German biologics registry (Biologika in der Kinderrheumatologie; BiKeR) were used as described previously ${ }^{11,22}$. The German BiKeR registry was a prospective cohort study conducted in accordance with the International Conference on Harmonization good clinical practices and the Declaration of Helsinki. The protocol had been approved by the ethics committee of the Aerztekammer Nordrhein, Duesseldorf, Germany, and by local ethics committees, if applicable according to local regulations. Written consent was obtained by the patients and their parents prior to the collection of the data. Data were collected through pseudonymization. All patients of the German JIA BiKeR registry who were newly starting treatment with biologicals or MTX from 2000 to April 2013 were included in our study. While patients treated with ETN were initially followed by registry, the documentation was extended to further biologics after abatacept (ABA), ADA, and tocilizumab (TCZ) were approved. Some patients' data from an earlier publication were included ${ }^{13}$.

The total JIA cohort of the registry was used to describe baseline demographic and clinical characteristics. Demographics were compared in patients with JIA with and without IBD. Patient data including adverse events were reported by the patient's local physician. Data of reported adverse events in the registry were explored to identify cases of IBD according to the European Society for Pediatric Gastroenterology Hepatology and Nutrition ESPGHAN Revised Porto Criteria. Medication at the time of development of IBD was reported, and IBD incidence with and without different drugs was compared by performing chi-square tests. Statistics were calculated with Microsoft Excel and Access.

\section{RESULTS}

From a total of 3071 patients in the registry and a total observation time of 8389 patient-years (PY), 11 cases of proven IBD were documented. Until March 31, 2013 (data lock), a total of 1739 patients starting ETN and 1126 patients starting treatment with MTX but never exposed to a biologic agent were identified in the database. There were 1912 patients who received 1 biologic only, and 298,87, 18, 2, and 2 patients who received 2, 3, 4, 5, and 6 biologics, respectively. TNF inhibitors were used as the first-line therapy in 1880 patients, and as second-line therapy in 232 and third-line therapy in 56. ETN was the first biologic agent in 1698 patients $(97.6 \%)$, second in $32(1.8 \%)$, and third in $9(0.5 \%)$.

There were 398 patients who were exposed to ADA (total exposure time $369 \mathrm{PY}$ ), and 44, 47, 47, and 50 patients who received ABA (25 PY), anakinra (68 PY), IFX, (37 PY), or TCZ (61 PY), respectively. The IBD incidence in patients with JIA in the registry was $1.31 / 1000$ patients.

Among 11 patients with IBD (27\% males), 8 had CD and 3 had UC, which matches the sex distribution of IBD subtypes in the pediatric population ${ }^{23}$. The IBD diagnosis was confirmed histologically according to the ESPGHAN Revised Porto Criteria for the diagnosis of IBD ${ }^{24}$ (Table 1). Two further cases of CD, 1 with extended oligoarthritis JIA and 1 with enthesitis-related arthritis (ERA) JIA, were reported, but had to be excluded because of missing diagnostic details. One patient was reported to have CD because of clinical, sonographic, and laboratory findings. One patient was reported to have developed CD with no further details given.

JIA categories in patients with IBD were extended oligoarthritis $(n=3)$, seronegative polyarthritis $(n=4)$, ERA $(\mathrm{n}=2)$, and psoriatic JIA $(\mathrm{n}=2)$. HLA-B27 was positive in 2 patients and not performed in 1 patient, and antinuclear antibodies (ANA) were positive in 7 patients developing an IBD. The characteristics of patients experiencing IBD were compared with the total JIA cohort (Table 2). There was no significant difference in sex, HLA-B27 positivity, or ANA positivity. The mean age at onset of JIA was $6.1 \pm 3.9$ years. Mean age at onset of IBD was $13.4 \pm 3.4$ years. Mean time between onset of JIA and onset of IBD was 7.2 \pm 4.0 years.

At admission to the registry, all of the 11 patients with JIA with new IBD were treated with NSAID and MTX. Seven patients were treated with steroids, 3 with sulfasalazine (SSZ), 2 with azathioprine, and 1 with leflunomide (LEF). At the time of IBD diagnosis, 9 patients were treated with ETN, 5 with NSAID, 3 with steroids, 2 with SSZ, and 1 with LEF. Two patients received MTX when IBD developed, 1 of them in combination with ETN; the other took MTX monotherapy and was never exposed to biologics. One patient developed IBD upon SSZ therapy after discontinuation of MTX therapy.

Analyzing the number of events and the exposure time of drugs revealed 5 IBD events occurring in 4575 years of exposure to NSAID (1.09/1000 PY), 3 in 1981 years of exposure to corticosteroids (1.51/1000 PY), 2 in 195 years of exposure to SSZ (10.26/1000 PY), 2 in 5455 years of exposure to MTX (0.37/1000 PY), 1 in 212 years of exposure to LEF (4.72/1000 PY), and 9 in 3557 years of exposure to ETN (2.53/1000 PY). In all 9 cases of IBD exposed to ETN, it was the first-line biologic therapy. One of the patients with reported but not proven CD had had monotherapy with ETN, and the other had received combination therapy with ETN and MTX. No occurrence of IBD was observed upon treatment with the other biologics. However, many fewer patients were followed with much shorter observation times compared to treatment with ETN.

The incidence of IBD was significantly lower in patients treated with MTX but significantly higher in patients treated with ETN or SSZ (Table 3). No statistical difference could be shown for treatment with corticosteroids, LEF, or NSAID.

Comparison of ETN monotherapy (1501 PY) with the combination treatment of ETN with MTX (1610 PY) showed that the incidence of an IBD event in patients receiving monotherapy with ETN (5.33/1000 PY) was much higher than with combination therapy $(0.62 / 1000 \mathrm{PY})$. The combination of ETN with MTX did not significantly increase the IBD incidence compared with MTX monotherapy (2670 PY, IBD incidence 0.37/1000 PY).

The 9 patients with ETN at the time of IBD diagnosis had Personal non-commercial use only. The Journal of Rheumatology Copyright (C) 2015. All rights reserved. 
Table 1. Patient overview including histological findings.

\begin{tabular}{|c|c|c|c|c|c|c|c|c|c|c|c|}
\hline No. & Sex & JIA Type & $\begin{array}{l}\text { Age at } \\
\text { JIA Onset, } \\
\text { Yrs }\end{array}$ & $\begin{array}{l}\text { IBD } \\
\text { Type }\end{array}$ & $\begin{array}{l}\text { Age at } \\
\text { IBD Onset, } \\
\text { Yrs }\end{array}$ & $\begin{array}{l}\text { Pretreatment at } \\
\text { Registry Start }\end{array}$ & $\begin{array}{l}\text { Medication at } \\
\text { IBD Onset }\end{array}$ & $\begin{array}{l}\text { Treatment } \\
\text { after IBD }\end{array}$ & $\begin{array}{c}\text { IBD } \\
\text { Outcome }\end{array}$ & $\begin{array}{c}\text { IBD } \\
\text { Diagnosis }\end{array}$ & $\begin{array}{l}\text { Histology } \\
\text { after } 3 \text { Mos }\end{array}$ \\
\hline 2 & $\mathrm{~F}$ & RF- JIA & 5.4 & $\mathrm{CD}$ & 10.2 & MTX, CS, NSAID & ETN & $\begin{array}{l}\text { Stop: ETN; } \\
\text { start: ADA, } \\
\text { MES, CS }\end{array}$ & No $R$ & $\begin{array}{l}\mathrm{H} \\
\mathrm{m}\end{array}$ & $\begin{array}{l}\text { Oesophagitis, epitheloid cell } \\
\text { reaction, and isolated giant cells; } \\
\text { active and chronic duodenitis with } \\
\text { microgranulomata, active and chronic } \\
\text { colitis with epitheloid cell reaction }\end{array}$ \\
\hline 3 & $\mathrm{~F}$ & eoJIA & 4.1 & $\mathrm{UC}$ & 12.0 & MTX, LEF, NSAID & ETN, LEF & $\begin{array}{l}\text { Stop: ETN; } \\
\text { start: MES, } \\
\text { ADA, CS }\end{array}$ & $\mathrm{R}$ & $\mathrm{H} \mathrm{E}$ & Erosive colitis, colonic cryptic defect \\
\hline 4 & $\mathrm{~F}$ & eoJIA & 6.7 & $\mathrm{CD}$ & 11.7 & MTX, CS, NSAID & ETN, NSAID & $\begin{array}{l}\text { Stop: ETN; } \\
\text { start: ADA, } \\
\text { SSZ, CS }\end{array}$ & $\mathrm{R}$ & $\mathrm{H}$ & $\begin{array}{l}\text { Colonic cryptic defect, loss of } \\
\text { goblet cells, cryptitis, inflammatory } \\
\text { infiltrate }\end{array}$ \\
\hline 6 & $\mathrm{~F}$ & ERA & 10.0 & $\mathrm{UC}$ & 17.2 & $\begin{array}{l}\text { MTX, AZA, SSZ, } \\
\text { CS, NSAID }\end{array}$ & SSZ, NSAID & SSZ ongoing & NA & $\mathrm{H}$ & $\begin{array}{l}\text { Chronic colitis with few ulcerative } \\
\text { and inflammatory reactive, small } \\
\text { adenomatous polypus }\end{array}$ \\
\hline 7 & M & PsA & 10.3 & $\mathrm{CD}$ & 17.9 & MTX, SSZ, NSAID & MTX, SSZ & $\begin{array}{c}\text { MTX and SSZ } \\
\text { ongoing }\end{array}$ & No $R$ & $\mathrm{H} \mathrm{A}$ & Aphthous ulcera in the terminal ileum \\
\hline 8 & $\mathrm{~F}$ & RF- JIA & 3.1 & $\mathrm{UC}$ & 11.9 & $\begin{array}{l}\text { MTX, AZA, } \\
\text { CS, NSAID }\end{array}$ & $\begin{array}{c}\text { ETN, CS, } \\
\text { NSAID }\end{array}$ & $\begin{array}{l}\text { Stop: ETN; } \\
\text { start: MTX, } \\
\text { IFX, SSZ }\end{array}$ & $\mathrm{R}$ & $\mathrm{H} \quad \mathrm{P}$ & Pancolitis ulcerosa, microgranuloma \\
\hline 9 & $\mathrm{~F}$ & eoJIA & 9.6 & $\mathrm{CD}$ & 11.4 & MTX, CS, NSAID & ETN & $\begin{array}{l}\text { Stop: ETN; } \\
\text { start: MTX, } \\
\text { CS, SSZ }\end{array}$ & No $R$ & $\begin{array}{rr}\mathrm{H} & \mathrm{Il} \\
& \mathrm{a} \\
\mathrm{a} & \end{array}$ & $\begin{array}{l}\text { Ileal chronic inflammatory infiltrate, } \\
\text { active lymphatic system, and Peyer } \\
\text { patch; colonic cryptic defect and } \\
\text { abscesses, erosions, chronic gastritis }\end{array}$ \\
\hline
\end{tabular}

JIA: juvenile idiopathic arthritis; IBD: inflammatory bowel disease; M: male; F: female; PsA: psoriatic arthritis; RF: rheumatoid factor; eoJIA: extended oligoarticular JIA; ERA: enthesitis-related arthritis; CD: Crohn disease; UC: ulcerative colitis; MTX: methotrexate; NSAID: nonsteroidal antiinflammatory drugs; CS: corticosteroid; LEF: leflunomide; AZA: azathioprine; SSZ: sulfasalazine; ETN: etanercept; MES: mesalazine; ADA: adalimumab; IFX: infliximab; R: remission; H: histological; NA: unknown.

a mean (median) exposure time of $1.71(1.29)$ years with a wide range of $0.34-5.03$ years before onset of IBD symptoms. Of interest, in 8 of them, IBD was reported after MTX was discontinued. IBD symptoms started within a mean (median, range) time of $2.05(1.29,0.50-6.08)$ years after discontinuation of MTX. ETN has been discontinued in 8 patients within a mean (median, range) time of $5.5(0.9$, 0.0-22.3) weeks after onset of IBD.

No patient went into remission after discontinuation only of ETN. All were treated for IBD, receiving standard care, including 4 patients who received $\mathrm{ADA}$ and 1 patient who received IFX.

\section{DISCUSSION}

The IBD incidence in patients with JIA in the registry was $1.31 / 1000$ PY and thus much higher than published IBD incidences in pediatric populations ${ }^{23,25,26,27,28}$. Because the methodology of those analyses was different from our method, direct comparison seems inappropriate.

According to our observation, patients with the newly approved JIA categories - extended oligoarthritis, ERA, and psoriatic arthritis (PsA) - were especially at risk because $64 \%$ of the patients with IBD belonged to these 3 JIA categories while their percentage in the total registry cohort was only $38 \%$. This observation is in line with the historical classification of PsA, late-onset HLA-B27-positive oligoarticular juvenile chronic arthritis, and arthritides in the context of IBD upon the covering term of the spondyloarthropathies, suggesting that these entities have common clinical and genetic features ${ }^{29}$. Subclinical gut inflammation similar to CD has been found in 40-60\% of patients with spondyloarthropathies, even if the number of symptomatic

Personal non-commercial use only. The Journal of Rheumatology Copyright ()$^{2015}$. All rights reserved. 
Table 2. Patient characteristics. Comparing patients with and without clinical characteristic using chi-square test. Differences were not statistically significant. Values are n (\%).

\begin{tabular}{lccc}
\hline Characteristics & $\begin{array}{c}\text { Total JIA Cohort, } \\
\text { of BiKeR patients }\end{array}$ & JIA without IBD & JIA with IBD \\
\hline Male & $998(32.5)$ & $995(32.4)$ & $3(27.3)$ \\
ANA+ & $1414(46.0)$ & $1407(45.8)$ & $7(63.6)$ \\
HLA-B27+ & $617(20.1)$ & $615(20.0)$ & $2(18.2)$ \\
sJIA & $197(6.4)$ & $197(6.4)$ & 0 \\
RF- JIA & $908(29.6)$ & $904(29.4)$ & $4(36.4)$ \\
RF+ JIA & $198(6.4)$ & $198(6.5)$ & 0 \\
poJIA & $501(16.3)$ & $501(16.4)$ & 0 \\
eoJIA & $502(16.3)$ & $499(16.2)$ & $3(27.3)$ \\
ERA & $427(13.9)$ & $425(13.8)$ & $2(18.2)$ \\
PsA & $237(7.7)$ & $235(7.7)$ & $2(18.2)$ \\
ucJIA & $100(3.3)$ & $100(3.3)$ & 0 \\
\hline
\end{tabular}

JIA: juvenile idiopathic arthritis; BiKeR: Biologika in der Kinder-rheumatologie (German biologics registry); IBD: inflammatory bowel disease; ANA: antinuclear antibodies; sJIA: systemic JIA; RF: rheumatoid factor; poJIA: persistent oligoarticular JIA; eoJIA: extended oligoarticular JIA; ERA: enthesitis-related arthritis; PsA: psoriatic arthritis; ucJIA: unclassified JIA.

IBD is estimated at only $7 \%^{21}$. Thus, according to former published cases ${ }^{14,15,16,17}$, the conclusion can be drawn that onset of IBD upon ETN therapy may be coincidental to preexisting spondyloarthropathies.

No IBD has been reported so far in patients with rheumatoid factor-positive polyarthritis and in patients with systemic arthritis. The increased IBD incidence after SSZ must be reviewed with the consideration that it is often used in patients with ERA, and the relationship of joint and gut inflammation has been previously described in pediatric spondyloarthropathy patients ${ }^{21}$. On the other hand, only 2 patients with IBD were carriers of HLA-B27.
Interestingly, patients with JIA treated with MTX showed a marked lower incidence of IBD in our registry, while those patients treated with ETN monotherapy or SSZ seemed at higher risk. However, the higher IBD incidence with SSZ (2 patients) must be evaluated carefully because of small numbers.

MTX has shown efficacy for treatment of IBD in adults and seems also to be effective in juvenile-onset $\operatorname{IBD}^{30,31}$. Thus, it may be protective against the new occurrence of IBD manifestations in patients with JIA of our cohort. Further, IBD events more often occurred after the discontinuation of MTX (9 events) than upon treatment with MTX (2 events). Pretreatment with MTX is required for the approval of treatment of polyarticular JIA with ETN. Thus, nearly all of the patients of the BiKeR registry who have been exposed to ETN were pretreated with MTX. Upon successful treatment of arthritis with ETN, MTX was eventually withdrawn, often without the risk of flare of arthritis.

The incidence of an IBD event is higher in patients treated with ETN monotherapy, compared with the combination treatment of MTX and ETN. All of the 8 patients treated with ETN monotherapy who had experienced an IBD event were previously treated with MTX. Thus, the discontinuation of MTX upon good clinical response of the arthritis in patients treated with ETN can lead to the occurrence of IBD in patients at risk. Because the rate of IBD events is not significantly different in patients treated with MTX monotherapy compared with those treated with the combination of MTX and ETN, there is no reason to conclude that ETN treatment itself causes IBD. This conclusion is based on 2670 years of exposure to MTX monotherapy and 1610 years of exposure to a combination of MTX and ETN in the BiKeR registry with the occurrence of 1 event of IBD, respectively.

Increased numbers of unexpected paradoxical events

Table 3. Incidence rates related to drug exposure. Data are given as exposed and not exposed to the drug without considering concomitant medication. Occurrence of IBD was positively associated to the exposure to SSZ and ETN, while MTX was protective.

\begin{tabular}{lccccccc}
\hline Drug Exposure & & IBD Cases, $\mathrm{n}$ & Exposure Yrs & $\begin{array}{c}\text { Incidence/ } \\
1000 \mathrm{PY}\end{array}$ & OR* & $95 \% \mathrm{CI}^{*}$ & $\mathrm{p}^{*}$ \\
\hline \multirow{2}{*}{ NSAID } & + & 5 & 4575 & 1.09 & 0.69 & $0.21-2.28$ & $\mathrm{NS}$ \\
& - & 6 & 3814 & 1.57 & & & \\
CS & + & 3 & 1981 & 1.51 & 1.21 & $0.32-4.58$ & NS \\
& - & 8 & 6409 & 1.25 & & & \\
SSZ & + & 2 & 195 & 10.26 & 9.34 & $2.05-43.51$ & $<0.05$ \\
& - & 9 & 8195 & 1.10 & & & \\
LEF & + & 1 & 212 & 4.72 & 3.86 & $0.49-30.27$ & NS \\
& - & 10 & 8178 & 1.22 & & & \\
MTX & + & 2 & 5455 & 0.37 & 0.12 & $0.03-0.55$ & $<0.05$ \\
& - & 9 & 2935 & 3.07 & & & \\
ETN & + & 9 & 3557 & 2.53 & 6.11 & $1.32-28.32$ & $<0.05$ \\
& - & 2 & 4833 & 0.41 & & &
\end{tabular}

\footnotetext{
* Chi-square test was performed for comparison of incidences with and without medication, respectively. IBD: inflammatory bowel disease; SSZ: sulfasalazine; ETN: etanercept; MTX: methotrexate; PY: patient-years; NSAID: nonsteroidal antiinflammatory drug; CS: corticosteroid; LEF: leflunomide; NS: not significant.
} 
involving TNF inhibitor therapy have been described, including not only onset of IBD but also new onset or exacerbation of psoriasis, uveitis, or aseptic granulomatous disease such as sarcoidosis ${ }^{32}$. This phenomenon of paradoxical inflammation has an estimated incidence of more than $10 \%$ in patients receiving TNF inhibitors ${ }^{33}$.

In our study, IBD occurred only during treatment with ETN, but not with other TNF inhibitors or biologics. In published cases, the onset of IBD with ETN therapy has been described more frequently than with other TNF inhibitors such as IFX $^{14,15,16,17}$. It was proposed that instead of leading to apoptosis in lamina propria T cells as IFX and ADA do, ETN leads to cytokine production, which includes TNF- $\alpha$ and interferon- $\gamma$. Further, binding of TNF- $\alpha$ to ETN is known to prolong the plasma half-life of the cytokine. These factors may favor the inflammation in the bowel mucosa and may result in granuloma formation, and thus lead to the development of new-onset IBD ${ }^{34,35,36}$. In patients with rheumatoid arthritis (RA), increased peripheral $\mathrm{T}$ cell activity both to self-antigens and to microbial antigens has been shown after ETN therapy ${ }^{37}$.

A common genetic pathway with an association between IBD and JIA has been demonstrated in large-scale studies $^{38,39,40}$. RA, JIA, and IBD have common genetic features. The REL locus, PRDM1/ATG5 locus, and FCGR $2 A$ locus are found to be associated with all of them ${ }^{41}$. In addition, in patients with RA and UC, the IL2/IL21, TNFRSF 14, and IRF5 loci are common. In patients with CD and RA, associations to the IL2RA locus have been found. In pediatric patients with IBD, CD was associated with a higher prevalence of RA (OR 15.7), systemic lupus erythematosus (OR 41.0), and hypothyroidism (OR 2.9) ${ }^{40}$.

A limitation of our approach to compare rates of adverse events between cohorts of patients treated with MTX and ETN with those treated with other nonbiologic DMARD and other biologics is that much lower exposure years for agents other than ETN and MTX have been documented in the registry. This has to be considered when judging the real risk of IBD from biologics.

Although the patient numbers reported here are, to our knowledge, the highest numbers available of patients with JIA exposed to biologics and followed prospectively to date, they may still be too small to finally answer this question. A common data analysis of all national registries and international cooperation within the Pharmachild registry may overcome this problem.

Because of the small number of cases, we were unable to use linear regression models to calculate the influence of distinct variables such as the JIA categories. This disadvantage may also be overcome by international collaboration.

The incidence of IBD in patients with JIA seems to be higher than in the general pediatric population. MTX therapy seems to be protective, while ETN seems not to be protective. While case numbers are still too small, further observation is necessary to explore IBD in patients with JIA. Because of the limited number of cases, no further statistical analysis was performed.

\section{ACKNOWLEDGMENT}

The authors acknowledge the collaboration of numerous German and Austrian pediatric rheumatologists, patients, and their parents.

\section{REFERENCES}

1. Manners PJ, Bower C. Worldwide prevalence of juvenile arthritis why does it vary so much? J Rheumatol 2002;29:1520-30.

2. Danner S, Sordet C, Terzic J, Donato L, Velten M, Fischbach M, et al. Epidemiology of juvenile idiopathic arthritis in Alsace, France. J Rheumatol 2006;33:1377-81.

3. Berntson L, Fasth A, Andersson-Gäre B, Kristinsson J, Lahdenne P, Marhaug G, et al; Nordic Study Group. Construct validity of ILAR and EULAR criteria in juvenile idiopathic arthritis: a population based incidence study from the Nordic countries. International League of Associations for Rheumatology. European League Against Rheumatism. J Rheumatol 2001;28:2737-43.

4. Beukelman T, Patkar NM, Saag KG, Tolleson-Rinehart S, Cron RQ, DeWitt EM, et al. 2011 American College of Rheumatology recommendations for the treatment of juvenile idiopathic arthritis: initiation and safety monitoring of therapeutic agents for the treatment of arthritis and systemic features. Arthritis Care Res 2011;63:465-82.

5. Horneff G, Foeldvari I, Minden K, Moebius D, Hospach T. Report on malignancies in the German juvenile idiopathic arthritis registry. Rheumatology 2011;50:230-6.

6. Dueckers G, Guellac N, Arbogast M, Dannecker G, Foeldvari I, Frosch M, et al. Evidence and consensus based GKJR guidelines for the treatment of juvenile idiopathic arthritis. Clin Immunol 2012;142:176-93.

7. Klein A, Kaul I, Foeldvari I, Ganser G, Urban A, Horneff G. Efficacy and safety of oral and parenteral methotrexate therapy in children with juvenile idiopathic arthritis: an observational study with patients from the German Methotrexate Registry. Arthritis Care Res 2012;64:1349-56.

8. Lovell DJ, Giannini EH, Reiff A, Cawkwell GD, Silverman ED, Nocton JJ, et al. Etanercept in children with polyarticular juvenile rheumatoid arthritis. Pediatric Rheumatology Collaborative Study Group. N Engl J Med 2000;342:763-9.

9. Lovell DJ, Reiff A, Ilowite NT, Wallace CA, Chon Y, Lin SL, et al Pediatric Rheumatology Collaborative Study Group. Safety and efficacy of up to eight years of continuous etanercept therapy in patients with juvenile rheumatoid arthritis. Arthritis Rheum 2008;58:1496-504

10. Quartier P, Taupin P, Bourdeaut F, Lemelle I, Pillet P, Bost M, et al. Efficacy of etanercept for the treatment of juvenile idiopathic arthritis according to the onset type. Arthritis Rheum 2003; 48:1093-101.

11. Horneff G, De Bock F, Foeldvari I, Girschick HJ, Michels H, Moebius D, et al; German and Austrian Paediatric Rheumatology Collaborative Study Group. Safety and efficacy of combination of etanercept and methotrexate compared to treatment with etanercept only in patients with juvenile idiopathic arthritis (JIA): preliminary data from the German JIA Registry. Ann Rheum Dis 2009; 68:519-25.

12. Brennan FM, Feldmann M. Cytokines in autoimmunity. Curr Opin Immunol 1992;4:754-9.

13. van Dijken TD, Vastert SJ, Gerloni VM, Pontikaki I, Linnemann K, Girschick H, et al. Development of inflammatory bowel disease in patients with juvenile idiopathic arthritis treated with etanercept. J Rheumatol 2011;38:1441-6.

14. Wiegering V, Morbach H, Dick A, Girschick HJ. Crohn's disease

Personal non-commercial use only. The Journal of Rheumatology Copyright (C) 2015. All rights reserved. 
during etanercept therapy in juvenile idiopathic arthritis: a case report and review of the literature. Rheumatol Int 2010;30:801-4.

15. Toussirot É, Houvenagel É, Goëb V, Fouache D, Martin A, Le Dantec P, et al. Development of inflammatory bowel disease during anti-TNF- $\alpha$ therapy for inflammatory rheumatic disease: a nationwide series. Joint Bone Spine 2012;79:457-63.

16. Gerloni V, Pontikaki I, Gattinara M, Fantini F. Focus on adverse events of tumour necrosis factor alpha blockade in juvenile idiopathic arthritis in an open monocentric long-term prospective study of 163 patients. Ann Rheum Dis 2008;67:1145-52.

17. Tarkiainen M, Tynjälä P, Vähäsalo $P$, Lahdenne P. Occurrence of inflammatory bowel disease in four patients with juvenile idiopathic arthritis receiving etanercept or infliximab. Scand J Rheumatol 2011;40:150-2.

18. Breese EJ, Michie CA, Nicholls SW, Murch SH, Williams CB, Domizio P, et al. Tumor necrosis factor alpha-producing cells in the intestinal mucosa of children with inflammatory bowel disease. Gastroenterology 1994;106:1455-66.

19. Peyrin-Biroulet L, Deltenre P, de Suray N, Branche J, Sandborn WJ, Colombel JF. Efficacy and safety of tumor necrosis factor antagonists in Crohn's disease: Meta-analysis of placebo-controlled trials. Clin Gastroenterol Hepatol 2008;6:644-53.

20. Sandborn WJ, Hanauer SB, Katz S, Safdi M, Wolf DG, Baerg RD, et al. Etanercept for active Crohn's disease: a randomized, double-blind, placebo-controlled trial. Gastroenterology 2001;121:1088-94.

21. Mielants H, Veys EM, Cuvelier C, De Vos M, Goemaere S, De Clercq L, et al. The evolution of spondyloarthropathies in relation to gut histology. III. Relation between gut and joint. J Rheumatol 1995;22:2279-84.

22. Horneff G, Schmeling H, Biedermann T, Foeldvari I, Ganser G, Girschick HJ, et al. The German etanercept registry for treatment of juvenile idiopathic arthritis. Ann Rheum Dis 2004;63:1638-44.

23. Sawczenko A, Sandhu BK, Logan RF, Jenkins H, Taylor CJ, Mian $\mathrm{S}$, et al. Prospective survey of childhood inflammatory bowel disease in the British Isles. Lancet 2001;357:1093-4

24. Levine A, Koletzko S, Turner D, Escher JC, Cucchiara S, de Ridder L, et al; European Society of Pediatric Gastroenterology, Hepatology, and Nutrition. ESPGHAN revised porto criteria for the diagnosis of inflammatory bowel disease in children and adolescents. J Pediatr Gastroenterol Nutr 2014;58:795-806.

25. Auvin S, Molinié F, Gower-Rousseau C, Brazier F, Merle V, Grandbastien B, et al. Incidence, clinical presentation and location at diagnosis of pediatric inflammatory bowel disease: a prospective population-based study in northern France (1988-1999). J Pediatr Gastroenterol Nutr 2005;41:49-55

26. Orel R, Kamhi T, Vidmar G, Mamula P. Epidemiology of pediatric chronic inflammatory bowel disease in central and western Slovenia, 1994-2005. J Pediatr Gastroenterol Nutr 2009;48:579-86.

27. Benchimol EI, Guttmann A, Griffiths AM, Rabeneck L, Mack DR, Brill $\mathrm{H}$, et al. Increasing incidence of paediatric inflammatory bowel disease in Ontario, Canada: evidence from health administrative data. Gut 2009;58:1490-7.
28. Jakobsen C, Paerregaard A, Munkholm P, Faerk J, Lange A, Andersen J, et al. Pediatric inflammatory bowel disease: increasing incidence, decreasing surgery rate, and compromised nutritional status: A prospective population-based cohort study 2007-2009. Inflamm Bowel Dis 2011;17:2541-50.

29. Arvonen M, Vähäsalo P, Turunen S, Salo HM, Mäki M, Laurila K, et al. Altered expression of intestinal human leucocyte antigen D-related and immune signalling molecules in juvenile idiopathic arthritis. Clin Exp Immunol 2012;170:266-73.

30. Turner D, Grossman AB, Rosh J, Kugathasan S, Gilman AR, Baldassano R, et al. Methotrexate following unsuccessful thiopurine therapy in pediatric Crohn's disease. Am J Gastroenterol 2007;102:2804-12.

31. Ardizzone S, Bollani S, Manzionna G, Imbesi V, Colombo E, Bianchi Porro G. Comparison between methotrexate and azathioprine in the treatment of chronic active Crohn's disease: a randomised, investigator-blind study. Dig Liver Dis 2003;35:619-27.

32. Fouache D, Goëb V, Massy-Guillemant N, Avenel G, Bacquet-Deschryver H, Kozyreff-Meurice M, et al. Paradoxical adverse events of anti-tumour necrosis factor therapy for spondyloarthropathies: a retrospective study. Rheumatology 2009;48:761-4.

33. Fiorino G, Danese S, Pariente B, Allez M. Paradoxical immune-mediated inflammation in inflammatory bowel disease patients receiving anti-TNF- $\alpha$ agents. Autoimmun Rev 2014; 13:15-9.

34. Van den Brande JM, Braat H, van den Brink GR, Versteeg HH, Bauer CA, Hoedemaeker I, et al. Infliximab but not etanercept induces apoptosis in lamina propria T-lymphocytes from patients with Crohn's disease. Gastroenterology 2003;124:1774-85.

35. Zou J, Rudwaleit M, Brandt J, Thiel A, Braun J, Sieper J. Up regulation of the production of tumour necrosis factor alpha and interferon gamma by $\mathrm{T}$ cells in ankylosing spondylitis during treatment with etanercept. Ann Rheum Dis 2003;62:561-4.

36. Shen C, Assche GV, Colpaert S, Maerten P, Geboes K, Rutgeerts P, et al. Adalimumab induces apoptosis of human monocytes: a comparative study with infliximab and etanercept. Aliment Pharmacol Ther 2005:21:251-8.

37. Berg L, Lampa J, Rogberg S, van Vollenhoven R, Klareskog L. Increased peripheral $\mathrm{T}$ cell reactivity to microbial antigens and collagen type II in rheumatoid arthritis after treatment with soluble TNFalpha receptors. Ann Rheum Dis 2001;60:133-9.

38. García Rodríguez LA, González-Pérez A, Johansson S, Wallander MA. Risk factors for inflammatory bowel disease in the general population. Aliment Pharmacol Ther 2005;22:309-15.

39. Bernstein CN, Wajda A, Blanchard JF. The clustering of other chronic inflammatory diseases in inflammatory bowel disease: a population-based study. Gastroenterology 2005:129:827-36.

40. Kappelman MD, Galanko JA, Porter CQ, Sandler RS. Association of paediatric inflammatory bowel disease with other immune-mediated diseases. Arch Dis Child 2011:96:1042-6.

41. Lees CW, Barrett JC, Parkes M, Satsangi J. New IBD genetics: common pathways with other diseases. Gut 2011:60;1739-53. 